\title{
Comparing Results of Alternate Format Test Questions to Standard Multiple Choice Test Questions in First, Second, and Third Year Baccalaureate Nursing Students
}

\author{
Elizabeth Hynes ${ }^{1}$ and Karen Street $^{2}$ \\ Centre for Nursing Studies, 100 Forest Road, St. John's, NL A1A 1E5, Canada \\ kstreet@mun.ca
}

\begin{abstract}
Multiple choice questions are frequently used on examinations within the health disciplines to evaluate student performance. Before 2015, Canadian nursing graduates were required to pass the Canadian Registered Nurse Exam (CRNE) to obtain licensure to practice. This exam consisted of mainly multiple-choice questions. In recent years, Canada (except for its province of Quebec) has adopted the NCLEX-RN exam as the licensure assessment exam for nursing graduates. The NCLEX-RN exam is a computer adaptive test that utilizes not only multiple choice questions, but also question items in a variety of other formats such as multiple responses, fill-in-the-blank calculation, ordered response, and hot spot. To explore if changes in question item formats influenced an individual's ability to answer a test question correctly, we carried out a descriptive, comparative study with first, second, and third-year Baccalaureate nursing students. We compared the students' performance on NCLEX-RN style alternate format test questions with their performance on standard multiple choice questions in an anatomy and physiology course. We further compared their performance on both types of questions and their final grade in the course. A convenience sample of students enrolled in one Atlantic Canadian Nursing Program was included. Descriptive statistics resulted in significant differences between the various types of questions used. The results of this study provide the basis for recommendations directed toward the inclusion of alternate format test questions on examinations throughout the current nursing curriculum as a means to enhance baccalaureate nursing students' performance on their future licensure exams.
\end{abstract}

Keywords: Nursing students, Multiple choice test questions, Alternate format test questions, NCLEX-RN exam

\section{Introduction}

The use of multiple choice questions on examinations is a common method of assessment in the health disciplines [1][2][3][4][5]. This format of questioning is frequently used as it can effectively and efficiently assess large numbers of students, be administered in a relatively short period [1][2], cover a broad range of subject matter, and be easily and objectively scored [2][6]. In nursing education, the use of multiple-choice questions on examinations is often used in combination with other methods of evaluating student performance [7][8].

Article history:

Received (April 10, 2019), Review Result (June 2, 2019), Accepted (July 4, 2019) 
Ultimately, all nursing students must pass a licensure exam at the end of their nursing education program to practice as registered nurses. In the United States, the NCLEX-RN exam has been the licensure exam that nursing graduates are expected to pass since 1978 as the final step to practice safely as a registered nurse [9][10][11]. Since 1994, the NCLEX-RN exam has been delivered as a computer-adaptive exam for licensure assessment in nursing [9]. More recently, Canadian nurse regulators adopted the NCLEX-RN exam in 2015 as the license-to-practice exam for Canadian nursing graduates. This exam is also currently offered in 10 countries around the world for domestic licensure in the United States [12]. The NCLEX-RN exam utilizes test question items in a variety of formats that include not only multiple choice questions, but also alternate format items including but not limited to "multiple responses, fill in the blank calculation, ordered response, and hotspot" [13]. Quinn et al. [11] suggest nurse educators must prepare nursing students to write the NCLEX-RN exam, and the National League of Nursing (NLN) [14] recognizes that faculty must assess students for competence using multiple approaches. Wendt and Kenny [15] state that "the use of alternate format items may allow examinees to demonstrate competencies differently while also enabling more authentic assessment of additional knowledge, skill, and abilities". Some authors also recommend that alternate format items be included in nursing education program exams [11][15]. We were interested in learning if changes in question item format had an impact on an individual's ability to answer a test question correctly. In this descriptive comparative study, we examined how Baccalaureate Nursing (BN) students in first, second, and third year performed on select multiple choice test questions compared to contentmatched alternate format test questions in an anatomy and physiology course. Students' final grades in this course were also compared to their performance in both test question types.

\section{Method}

\subsection{Study design}

This descriptive, comparative study was designed to determine how first, second, and third-year Baccalaureate Nursing $(\mathrm{BN})$ students perform on standard multiple choice questions and to compare these results with their performance on alternate format test questions in an anatomy and physiology course. Students completed four multiple-choice questions and four alternate format test items which were matched to test the same anatomy and physiology content. First-year BN students completed the four multiple-choice questions as part of the regular term test in their anatomy and physiology course. The four alternate format test questions were administered with their term test in the form of bonus questions for extra credit. Students who choose not to complete the alternate format test questions were not negatively affected. If students choose not to participate in the study but wished to complete the bonus questions, they were asked to indicate on the alternate format test question their desire to be excluded. If students choose not to complete the bonus alternate format test questions, this also indicated that they did not wish to participate in the study.

The second and third-year BN students were invited to complete the same anatomy and physiology questions that the first-year nursing students completed, but these questions were not part of the normal evaluative criteria for second and third-year students. All questions were reviewed by faculty familiar with the anatomy and physiology course subject matter to ensure question content consistency between each multiple-choice question and the matched alternate format test question. The multiple choice questions were also assessed for item difficulty ( $\mathrm{P}$ value) and item discrimination $\left(\mathrm{r}_{\mathrm{pbis}}\right)$ [Table 1]. As well, all item distractors 
(options) in the multiple-choice questions were plausible answer choices in that all were selected by students as possible correct answers (as determined by item analysis).

Table 1. Multiple choice item difficulty and discrimination

\begin{tabular}{|c|c|c|}
\hline Multiple Choice Question & P value & Point biserial (rpbis) \\
\hline$\# 1$ & 0.813 & 0.254 \\
\hline$\# 2$ & 0.806 & 0.540 \\
\hline$\# 3$ & 0.694 & 0.461 \\
\hline$\# 4$ & 0.656 & 0.562 \\
\hline
\end{tabular}

\subsection{Research questions}

How does first, second, and third-year BN students' performance on standard multiple choice test questions compare to their performance on alternate format test questions?

How does first, second, and third-year BN students' performance on multiple choice test questions compare to their final grade in an Anatomy and Physiology course?

How does first, second, and third-year BN students' performance on alternate format test questions compare to their final grade in an Anatomy and Physiology course?

Is there a difference among first, second, and third-year BN students' performance on standard multiple-choice test questions?

Is there a difference among first, second, and third-year BN students' performance on alternate format test questions?

\subsection{Sample}

A convenience sample of students enrolled in one nursing program at an Atlantic Canadian university was included. There were 120 first-year, 122 second-year, and 122 third-year students invited to participate in the study. This number was sufficient to determine significant differences for an effect size of 0.35 (power $=0.80$, alpha $=0.05$ ). Ultimately, 119 first-year, 43 second-year, and 63 third-year students participated in the research, resulting in an overall response rate of $61.81 \%(n=225)$. This resulted in an effect size of 0.60 [16].

\subsection{Data analysis}

SPSS Version 21 was used to analyze the quantitative data. Data were analyzed using descriptive and non-parametric statistics (Chi-squared \& Spearman's Rho).

\subsection{Ethical considerations}

Before the study's commencement, ethical review and approval were obtained from the provincial Health Research Ethics Authority (HREA) and the Regional Health Authority Research Proposals Approval Committee (RPAC). Permission to access the student population was obtained through the administration of the school of nursing. Participation in this study was voluntary. Initially, students were asked to include their student number on the test question form to match their multiple choice question responses and their alternate format test question responses to their term grades in the course. The student numbers were coded and the data was entered into the statistical program. The student numbers were then removed by the nursing school's research assistant who had no access to any information associated with the student number. The final results were reported anonymously. Completion of the test questions indicated consent to participate. 


\section{Results}

Results of this study demonstrate significant relationships between students' correct responses on the multiple choice questions and correct responses on the alternate format test questions in all three years of the program. Students who correctly answered the multiple choice questions were more likely to answer the alternate format test questions correctly (see Table 2). The percentage of students able to correctly answer both the multiple choice questions and the alternate format test questions decreases from Year 1 to Year 3.

Table 2. Multiple Choice (MC) and Alternate Format (AF) scores by percentage

\begin{tabular}{|c|c|c|c|c|c|c|c|c|c|c|c|}
\hline & \multicolumn{9}{|c|}{ \# of Multiple Choice Questions Correct } & \multicolumn{3}{c|}{ \# of Alternate Format Questions Correct } & rs (p) \\
\cline { 2 - 12 } & 0 & 1 & 2 & 3 & 4 & 0 & 1 & 2 & 3 & 4 & \\
\hline $\begin{array}{c}\text { Year 1 } \\
(\mathrm{n}=119)\end{array}$ & 0 & 6.7 & 19.3 & 31.9 & 42 & .8 & 10.9 & 41.2 & 31.1 & 16 & $.52(.000)$ \\
\hline $\begin{array}{c}\text { Year 2 } \\
(\mathrm{n}=43)\end{array}$ & 4.7 & 23.3 & 37.2 & 27.9 & 7 & 11.6 & 53.5 & 34.9 & 0 & 0 & $.60(.000)$ \\
\hline $\begin{array}{c}\text { Year 3 } \\
(\mathrm{n}=63)\end{array}$ & 9.5 & 22.2 & 47.6 & 17.5 & 3.2 & 27 & 57.1 & 14.3 & 1.6 & 0 & $.35(.005)$ \\
\hline
\end{tabular}

The multiple-choice question one and corresponding fill-in-the-blank questions were positively and significantly related in all three years of the program [Table 3]. Students in all three years who correctly answered the multiple choice question one were more likely to correctly answer the corresponding fill-in-the-blank question.

Table 3. Multiple Choice question 1 vs. Fill In The Blank

\begin{tabular}{|c|c|c|c|}
\hline & Multiple Choice 1 & Fill In the Blank 1 & rs (p) \\
\hline Year 1 $(\mathrm{n}=119)$ & $86 \%$ & $89 \%$ & $.70(.000)$ \\
\hline Year 2 $(\mathrm{n}=43)$ & $42 \%$ & $40 \%$ & $.76(.000)$ \\
\hline Year 3 $\mathrm{n}=63)$ & $32 \%$ & $25 \%$ & $.62(.000)$ \\
\hline
\end{tabular}

The multiple choice question two and the corresponding hotspot question were positively and significantly related for students in the first and third years, and approached significance for students in the second year [Table 4]. Students who correctly answered the multiple choice question two were more likely to correctly answer the corresponding hotspot question.

Table 4. Multiple Choice question 2 vs. Hot Spot

\begin{tabular}{|c|c|c|c|}
\hline & Multiple Choice 2 & Hot Spot 2 & rs (p) \\
\hline Year 1 $(\mathrm{n}=119)$ & $68 \%$ & $62 \%$ & $.28(.002)$ \\
\hline Year 2 $(\mathrm{n}=43)$ & $63 \%$ & $67 \%$ & $.29(.062)$ \\
\hline Year 3 $(\mathrm{n}=63)$ & $41 \%$ & $60 \%$ & $.35(.005)$ \\
\hline
\end{tabular}

When comparing the multiple choice question three to the matched choose-all-that-apply question, findings indicated that this question was positively and significantly related for firstyear students, but not for students in second and third years [Table 5]. 
Table 5. Multiple Choice question 3 vs. Choose all that apply

\begin{tabular}{|c|c|c|c|}
\hline & Multiple Choice 3 & Choose all that apply 3 & rs (p) \\
\hline Year 1 $(\mathrm{n}=119)$ & $68 \%$ & $36 \%$ & $.39(.000)$ \\
\hline Year 2 $(\mathrm{n}=43)$ & $37 \%$ & $5 \%$ & $.29(.062)$ \\
\hline Year 3 $(\mathrm{n}=63)$ & $57 \%$ & $3 \%$ & $.16(.220)$ \\
\hline
\end{tabular}

Similarly, when comparing the multiple choice question four to the matched choose-allthat-apply question, findings also indicated that the question was positively and significantly related for first-year students, but not for students in second and third years [Table 6].

Table 6. Multiple Choice question 4 vs. Choose all that apply

\begin{tabular}{|c|c|c|c|}
\hline & Multiple Choice 4 & Choose all that apply & rs (p) \\
\hline Year 1 $(\mathrm{n}=119)$ & $87 \%$ & $63 \%$ & $.50(.000)$ \\
\hline Year 2 $(\mathrm{n}=43)$ & $67 \%$ & $12 \%$ & $.25(.103)$ \\
\hline Year 3 $(\mathrm{n}=63)$ & $52 \%$ & $2 \%$ & $.12(.344)$ \\
\hline
\end{tabular}

Anatomy and physiology grades for all three years were similar across the cohorts examined [Table 7]. Chi-squared testing indicated that anatomy and physiology grades were significantly related to success in answering all question types for first-year students but not for second and third-year students. First-year students did significantly better on the multiple choice questions $\left(\chi^{2}=67.44, \mathrm{df}=8, \mathrm{p}<.001\right)$ and alternate format questions $\left(\chi^{2}=119.228, \mathrm{df}\right.$ $=8, \mathrm{p}<.001)$ than did students in the second and third-year.

Table 7. Relationship between anatomy \& physiology grades and correct responses in different question types $(* \mathrm{p}<.05, * * \mathrm{p}<.01, * * * \mathrm{p}<.001)$

\begin{tabular}{|c|c|c|c|}
\hline & $\begin{array}{c}\text { Anatomy \& Physiology } \\
\text { Grade Mean }\end{array}$ & $\begin{array}{c}\text { Multiple Choice Question } \\
\text { Type (overall mean for the } \\
\text { 4 MC questions) }\end{array}$ & $\begin{array}{c}\text { Alternate Format Question } \\
\text { Type (overall mean for the } \\
\text { 4 AF questions) }\end{array}$ \\
\hline $\begin{array}{c}\text { Year 1 } \\
(\mathrm{n}=119)\end{array}$ & 73.15 & $3.09 * * *$ & $2.50 * * *$ \\
\hline $\begin{array}{c}\text { Year 2 } \\
(\mathrm{n}=43)\end{array}$ & 74.84 & 2.09 & 1.2 \\
\hline $\begin{array}{c}\text { Year 3 } \\
(\mathrm{n}=63)\end{array}$ & 74.83 & 1.8 & .90 \\
\hline
\end{tabular}

\section{Discussion}

The multiple choice questions used in this study tested some of the course content related to the first-year BN students' anatomy and physiology course and were part of the course term exam. All students (first, second, and third year) would have learned this material during the first-semester anatomy and physiology course in Year 1 of their BN program.

Classical Test Theory (CTT) proposes that multiple choice questions on any given examination should have a range of difficulty, with item difficulty determined by the proportion of test candidates answering the item correctly (called the P-value)[1][17]. An exam question with a $\mathrm{P}$-value between $\mathrm{P}>0.2$ and $\mathrm{P}<0.8$ is considered to be an acceptable test item, with values $\mathrm{P}<0.2$ being too difficult and $>0.8$ being too easy [1]. Oermann and Gaberson [18] suggest the desired P-value for most tests should be in the 0.3 to 0.7 range. 
However, the University of Washington, Office of Educational Assessment [19] recommends caution in interpreting item analysis results because statistics "must always be interpreted in the context of the type of test given and the individuals being tested." The multiple-choice questions used in this study had $\mathrm{P}$-values ranging from $\mathrm{P}=0.656-0.813$ [Table 1]. Two items had a moderate level of difficulty and two items were somewhat easier.

CTT also suggests that multiple-choice items should discriminate positively between examinees with high and low levels of knowledgeability, a term referred to as a point biserial correlation or $r_{p b i s}$ [1][16]. The discrimination index is indicative of the quality of a test item and ranges from -1.00 to +1.00 , with a higher positive value representative of a better item [18]. Thompson [17] states that a point biserial correlation value of " 0.2 means a decent item, and highly discriminating items will have values in the 0.5 or 0.6 range". McGahee and Ball [20] differ slightly in their interpretation of these values, indicating that questions with a point biserial between 0.2 and 0.3 are "fair", whereas test items with a point biserial between 0.4 and 0.7 are "good". The four multiple-choice questions used for this study had positive point biserial correlations, with two items in the highly discriminating range, and all four items within a desirable range [Table 1].

For this study, the four multiple choice questions utilized were matched with the anatomy and physiology course content with the four alternate format test questions. Alternate format test items were chosen based on some of the item types tested on the NCLEX-RN exam. Multiple choice question one was matched with a fill-in-the-blank question, and multiple choice question two was matched with a 'hot spot' type question. A hot spot question requires test takers to identify one or more locations on a picture or graphic [9] Multiple choice questions three and four were matched with multiple response test items. These alternate format test questions were developed by the researchers based on knowledge of the types of examination questions students could encounter on the NCLEX-RN exam.

Results of this study demonstrate significant relationships between students' correct responses on the multiple choice questions and correct responses on the alternate format test questions in all three years of the program. Students who answered the multiple choice questions correctly were more likely to answer the alternate format test questions correctly [Table 2]. This seems a reasonable finding, as students with greater knowledgeability should be able to perform well on questions covering the same content area, even if the questions are presented in a different format.

For students in the first year, $42 \%$ were able to correctly answer all four multiple-choice questions, whereas only $16 \%$ were able to correctly answer all four alternate format test question types. When comparing the correct number of multiple choice questions answered by the first-year students by percentage to the alternate format test questions, a similar percentage $(41.2 \%)$ of these students were able to correctly answer only two of the alternate format test questions. For students in the second and third years of the program, the greatest percentage of multiple choice questions answered correctly was two out of four $(37.2 \%$ in Year 2, and $47.6 \%$ in Year 3), while the greatest percentage of alternate format questions answered correctly was one out of four $(53.5 \%$ in Year 2, and $57.1 \%$ in Year 3). Therefore, students in all three years performed better in correctly answering the multiple choice questions than they did in correctly answering the alternate format test questions. As students in the BN program were generally more familiar with exam questions in the multiple choice question format, this may have contributed to these results. Two of the four alternate format test questions were multiple response items. This method of testing tends to encourage higher-order cognitive thinking processes than single-response test items [15] thus, some students may have had more difficulty answering those questions correctly. 
As indicated in [Table 2], the percentage of students able to correctly answer both the multiple choice questions and the alternate format test questions decreases from Year 1 to Year 3. A report issued by the American Society for Clinical Pathology (ASCP) [21] suggests that delays in writing certification exams in various professional disciplines can harm test performance scores. As well, a study investigating lag time and NCLEX pass rates found an inverse relationship between candidate success and time delay before writing the NCLEX exam[22]. While the students participating in this study were not invested in writing a licensure examination, there was a decline in their performance in correctly answering the test questions the further they progressed from Year 1 where they were initially taught the anatomy and physiology course material.

The results of responses by individual question type were also compared by student year in the BN program. The multiple-choice question one and corresponding fill-in-the-blank questions were positively and significantly related in all three years of the program [Table 3]. Students in all three years who correctly answered the multiple choice question one were more likely to correctly answer the corresponding fill-in-the-blank question, with findings indicating similar percentages of students by year of the program correctly answering the items in either question format. As fill-in-the-blank type questions have a similar response time as multiple choice type items [15] students may have perceived a similar level of item difficulty. Alternately, the item difficulty for the multiple choice question one was found to be $\mathrm{P}=0.813$, indicative of an easier test question. Therefore, the matched fill-in-the-blank item may have simply been an easier question for students to answer correctly.

The multiple choice question two and corresponding hotspot questions were also positively and significantly related for students in the first and third years, and approached significance for students in the second year. The Year 2 results may have been affected by the smaller sample size of second-year students in comparison to the other samples [Table 4]. Students who correctly answered the multiple choice question two were more likely to correctly answer the corresponding hotspot question. There were similar percentages of students by year of the program answering this question correctly in either format as well, except for the third year where students seemed to find the hotspot question easier ( $41 \%$ answered the multiple choice question correctly versus $60 \%$ answered the hotspot question correctly). This information supports the findings of a study on alternate format items by Wendt and Kenny [15]. Participants in that study liked hotspot items because they provided visual assistance. As well, a large percentage of Registered Nurses (RNs) and Licensed Practical Nurses (LPNs) in that study rated hotspot format question items as less difficult or at the same level of difficulty as a multiple choice item. The data from the questions administered for this research project suggests student participants did not find the alternate format items in either the fill-in-theblank or hotspot format any more challenging than they found the multiple choice test items.

When comparing the multiple choice questions three and four to the matched choose-allthat-apply questions three and four, findings indicated that these questions were positively and significantly related for first-year students, but not for students in second and third years [Table 5] and [Table 6]. Students in the first year who correctly answered the multiple choice questions three and four were more likely to correctly answer the corresponding choose-allthat-apply questions. There was no significant correlation for either of these questions for second and third-year students. One possible explanation for this is that first-year students answered the four multiple-choice questions as part of their term anatomy and physiology test, and could choose to answer the alternate format questions for bonus marks. Thus they had a vested interest in answering the questions correctly. Students in the second and third years were invited to answer test questions in both formats as research participants only, with 
no benefits or harm related to correctly answering the questions. As previously discussed, the literature suggests that time delays in completing examinations for some professional programs can harm exam scores [21][22]. The time interval between student learning of the anatomy and physiology concepts tested and student participants answering the test items for this study increased from the first to the third year. First-year students were immersed in the study of anatomy and physiology concepts as part of their current theoretical course work and as such would likely be able to more easily apply information related to those concepts to various question types. Although students are expected to then apply the content and concepts learned in first-year anatomy and physiology to future nursing courses, the second and thirdyear students were further from the specific detail of the course content and may have been more focused on other courses in their curriculum.

Data from this study indicated that the percentages of students able to correctly answer the choose-all-that-apply questions three and four declined in comparison to the percentages of students able to correctly answer the multiple choice questions three and four. In all cases, there was also a decrease in percentages of students answering the choose-all-that-apply questions correctly by year of the program, in that students in year one performed better on the choose-all-that-apply questions than students in year two, and students in year two performed better than students in year three. The literature indicates that alternate format test questions have been used in high-stakes examinations such as the NCLEX-RN as they are believed to encourage critical thinking and allow testing at higher levels of cognitive ability[8][13]. Further, multiple-response test items are more in-depth, more realistic, and more challenging [15]. This may explain why students in all three years of the program did not perform as well on the choose-all-that-apply test items three and four as they did on the multiple choice questions three and four.

Anatomy and physiology grades for all three years were similar across the cohorts examined [Table 7]. Chi-squared testing indicated that anatomy and physiology grades were significantly related to success in answering all question types for first-year students but not for second and third-year students. Again, this result could be explained by student investment in the anatomy and physiology course in the first year, their level of immersion in the course content, and the timing of administration of the test items relative to student learning of the course content. There were no significant relationships between second and third-year students' performance on the multiple choice or alternate format test questions and their anatomy and physiology grades. Recall, these students had voluntarily agreed to participate in the study and had no benefit or harm related to answering the test items correctly. Despite this, in all cases, students in the first, second, and third years did not perform as well on the alternate format test question types as they did on the multiple-choice questions (see Table 7). This would seem likely related to the higher cognitive level of the alternate format test questions in the choose-all-that-apply structure.

\section{Limitations}

First-year students answered the multiple choice questions as part of their anatomy and physiology term exam. The student's grades were calculated based on the number of multiplechoice questions they answered correctly. No marks were deducted for answering the questions incorrectly regardless of format. These students could also earn bonus marks on this same exam by answering the alternate format questions correctly. This would have provided first-year students with a greater incentive to answer the questions correctly. The small sample size of second-year students may have influenced the results. Alternate format 
test questions were developed by the researchers based on some of the question types examined on the NCLEX-RN exam. These questions, while similar, may not reflect the true difficulty or format of actual NCLEX-RN test items.

\section{Conclusions}

Nurse educators have a responsibility to ensure students become competent practitioners, and multiple sources of evidence are necessary to evaluate this competence [14]. Many nursing education programs rely on tests to determine student grades in particular courses as they progress through a program, so test questions must be reliable and valid. More research is needed to discover ways to improve the reliability and validity of test questions for nursing students and to encourage critical thinking using higher-order questions. To prepare nursing students for success on licensure examinations, it would be prudent for nurse educators to expose students to alternate format test questions, similar to those they might encounter on licensure exams, throughout their educational program [8]. This may also hold for internationally educated nurses required to write the NCLEX-RN exam for employment in North America. Faculty should endeavor to include exam test questions in a variety of formats to increase student exposure to multiple types of questions. Data from this study indicate that the longer the length of time from exposure to learned material, the less likely students will successfully answer the test items. Students should be provided the opportunity to write the NCLEX-RN licensure examination as soon as possible after the completion of their nursing program to maximize success, as there is a correlation between lag time and pass rates [22]. Students should also be provided the opportunity to practice various alternate format test questions similar to those they might encounter on the NCLEX-RN exam throughout their nursing program, particularly those in the multiple-response format, for them to internalize testing methods that encourage critical thinking skills and promote success in obtaining licensure to practice.

\section{References}

[1] G. T. Brown and H. A. Abdulnabi, "Evaluating the quality of higher education instructor-constructed multiple-choice tests: Impact on student grades," Frontiers in Education, vol.2, article no.24, pp.1-11, (2017)

[2] P. N. K. Lau, S. H. Lau, K. S. Hong, and H. Usop, "Guessing, partial knowledge, and misconceptions in multiple-choice tests," Educational Technology and Society, vol.14, no.4, pp.99-110, (2011)

[3] R. M. Epstein, “Assessment in medical education,” New England Journal of Medicine, vol.356, pp.387-396, (2007)

[4] M. Tarrant, A. Kneirim, S. Hayes, and J. Ware, "The frequency of item writing flaws in multiple-choice questions used in high stakes nursing assessments," Nurse Education in Practice, vol.6, pp.354-363, (2006)

[5] J. Considine and S. Thomas, "Design, format, validity and reliability of multiple choice questions for use in nursing research and education," vol. 12, no.1, pp.19-24, (2005)

[6] M. G. Simkin and W. L. Kuechler, "Multiple choice tests and student understanding: What is the connection?," Decision Sciences Journal of Innovative Education, vol.3, no.1, pp.73-97, (2005)

[7] A. M. Brady, "Assessment of learning with multiple-choice questions," Nurse Education in Practice, vol.5, pp.238-242, (2005)

[8] S. Birkhead, G. Kelman, B. Zittel, and L. Jatulis, "The prevalence of multiple-choice testing in registered nurse qualifying nursing education programs in New York state,” Nursing Education Perspectives, vol.39, no.3, pp.139-144, (2018)

[9] National Council of State Boards of Nursing (NCSBN), "Pencils down, booklets closed," The evolution of the NCLEX: 20 years as a computer adaptive exam, In Focus, Illinois: Author, (2014) 
[10] S. Bonis, L. Tart, and M. C. Wendler, "Strategies to promote success on the NCLEX-RN: An evidence-based approach using the ACE star model of knowledge transformation," Nursing Education Perspectives, vol.28, no.2, pp.82-87, (2007)

[11] B.L. Quinn, M. Smolinski, and A. Bostain Peters, "Strategies to improve NCLEX-RN success: A review," Teaching and Learning in Nursing, vol.13, pp.18-26, (2018)

[12] D. Kappel, "NCSBN opens registration for NCLEX in Canada," National Council of State Boards of Nursing (NCSBN) News Release, (2014)

[13] National Council of State Boards of Nursing (NCSBN), "2016 NCLEX-RN detailed test plan - Educator version,” [Online] Available: https://www.ncsbn.org/2016_RN_DetTestPlan_Educator.pdf, (2016)

[14] National League of Nursing (NLN), "The fair testing imperative in nursing education," NLN Vision Series, New York: Author, (2012)

[15] A. Wendt and L. E. Kenny, “Alternate item types: Continuing the quest for authentic testing," Journal of Nursing Education, vol.48, no.3, pp.150-156, (2009)

[16] D. F. Polit and C. T. Beck, "Nursing research: Generating and assessing evidence for nursing practice," $10^{\text {th }}$ edition, Wolters Kluwer, Philadelphia, (2016)

[17] N. Thompson, "Introduction to classical test theory," Assessment Systems Corporation Publication, (2016)

[18] M. H. Oermann and K. B. Gaberson, "Evaluation and testing in nursing education," 4th edition, Springer Publishing Company, New York, (2014)

[19] University of Washington Office of Educational Assessment, "Understanding item analyses," [Online] Available: www.washington.edu/assessment/scanning-scoring/reports/item-analysis

[20] T. W. McGahee and J. Ball, "How to read and use an item analysis," Nurse Educator, vol.34, no.4, pp.166171, (2009)

[21] ACSP Board of Certification Research and Development Committee, "Impact of time-lapse on ASCP board of certification medical laboratory scientist (MLS) and medical laboratory technician (MLT) examination scores," Lab Medicine, vol.46, no.3, pp.e53-e58, (2015)

[22] A. Woo, A. Wendt, and W. Liu, "NCLEX pass rates: An investigation into the effects of lag time and retake attempts," JONA'S Healthcare Law, Ethics, and Regulation, vol.11, no.1, pp.23-26, (2009)

\section{Authors}

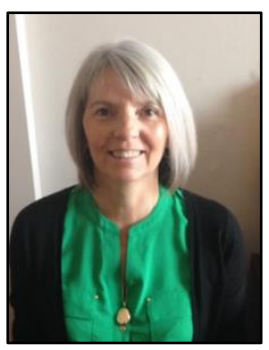

\section{Elizabeth Hynes}

She is a faculty member at the Centre for Nursing Studies in St. John's, NL, Canada. She has a clinical background in medical/surgical nursing and her research interests include professionalism and professional identity amongst registered nurses and student nurses.

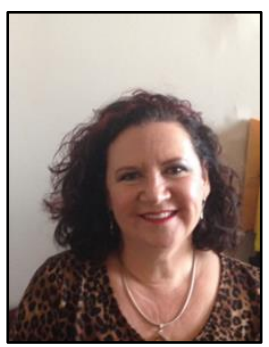

\section{Karen Street}

She is a faculty member at the Centre for Nursing Studies in St. John's, NL, Canada. She has a clinical background in medical/surgical nursing and her research interests include professionalism and professional identity amongst registered nurses and student nurses. 